\title{
The Co-Evaluation of Endometrial Karyorrhexis and Uterus Congestion after Erythropoietin Effect on Uterine Ischemia Reperfusion Injury
}

\author{
Tsompos $\mathrm{C}^{1 *}$, Panoulis $\mathrm{C}^{2}$, Toutouzas $\mathrm{K}^{3}$, Triantafyllou $\mathrm{A}^{4}$, Zografos $\mathrm{CG}^{3}$ and Papalois $\mathrm{A}^{5}$ \\ ${ }^{1}$ Department of Gynecology, General Hospital of Thessaloniki "St. Dimitrios" Thessaloniki, Greece \\ ${ }^{2}$ Department of Obstetrics \& Gynecology, Aretaieion Hospital, Athens University, Athens, Attiki, Greece \\ ${ }^{3}$ Department of Surgery, Ippokrateion General Hospital, Athens University, Athens, Attiki, Greece \\ ${ }^{4}$ Department of Biologic Chemistry, Athens University, Athens, Attiki, Greece \\ ${ }^{5}$ Experimental Research Centre ELPEN Pharmaceuticals, SA Inc., Co., Pikermi, Attiki, Greece
}

"Corresponding author: Tsompos Constantinos, Consultant A, Department of Gynecology, General Hospital of Thessaloniki "St. Dimitrios" Thessaloniki, Greece, Tel: 00302313322100; E-mail: tsomposconstantinos@gmail.com

Received: 13 Nov, 2017 | Accepted: 09 Jan, 2018 | Published: 18 Jan, 2018

Citation: Tsompos C, Panoulis C, Toutouzas K, Triantafyllou A, Zografos CG, et al. (2018) The Co-Evaluation of Endometrial Karyorrhexis and Uterus Congestion after Erythropoietin Effect on Uterine Ischemia Reperfusion Injury. J Network Med Target Ther 1(2): dx.doi.org/10.16966/2577-1906.108

Copyright: (c) 2018 Tsompos C, et al. This is an open-access article distributed under the terms of the Creative Commons Attribution License, which permits unrestricted use, distribution, and reproduction in any medium, provided the original author and source are credited.

\section{Abstract}

Aim: This study co-evaluated the 2 quoted histologic variables after erythropoietin (Epo) administration. The calculation was based on the results of 2 preliminary studies, each one evaluating a respective histologic variable of endometrial karyorrhexis (EK) or uterus congestion (UC) in an induced ischemia reperfusion (IR) animal experiment.

Materials and methods: The 2 main experimental endpoints at which the EK and UC scores were evaluated the reperfusion $60^{\text {th }} \mathrm{min}$ (for A \& C groups) and the reperfusion $120^{\text {th }}$ min (for B \& D groups). Specially, the groups $A$ and $B$ were processed without drugs, whereas the groups $C$ and $D$ after Epo administration.

Results: The first preliminary study showed that Epo non-significantly reduced the EK scores by without lesions $0.2727273 \pm 0.17222171$ ( $p$-value $=0.1102$ ). The other preliminary study showed that Epo also non-significantly reduced the UC scores by without lesions $0.0090909 \pm 0.12689199$ ( $p$-value $=0.9414)$. Both studies were co-estimated since they belong to the same experimental setting. This study co-evaluated the combined diagnostic values of both variables together.

Conclusions: Epo has a non-significant recessing potency for these histological parameters at the "without lesions" grade $0.1409091 \pm 0.12249148$ ( $p$-values $=0.2421)$ since they were coevaluated together.

Keywords: Ischemia; Erythropoietin; Endometrial karyorrhexis; Uterus congestion; Reperfusion

\section{Introduction}

Erythropoietin (Epo) was investigated whether having antioxidant capacities. 2 histologic variables in a uterine ischemia reperfusion (UIR) experiment were tested for this purpose. The one variable was that of endometrial karyorrhexis (EK) which was recessed by without lesions $0.2727273 \pm$ 0.17222171 ( $p$-value $=0.1102$ ) [1]. The other variable was that of uterus congestion (UC) and was restored by without lesions $0.0090909 \pm 0.12689199$ ( $p$-value $=0.9414$ ) [2]. Although Epo is met in over 29,895 published biomedical studies, only a $3.51 \%$ of them negotiate its antioxidant capacities. The present experimental work tried to co-evaluate these EK and UC variables together and to compare its outcome with each one separately, from the same rat induced UIR protocol.

\section{Materials and Methods}

\section{Animal Management}

The Vet No 3693/12-November-2010 \& 14/10-Januaru-2012 licenses, the auspices company, the experimental location and the Pathology Department are mentioned in preliminary references [1,2]. The human animal care of female Wistar Albino rats, the one week pre-experimental ad libitum diet, the intra-experimental anesthesiologic techniques, the acidometry, the electrocardiogram and the oxygen supply and post-experimental euthanasia are also described in preliminary references. General anaesthesia was induced by initial IM administration of $0.5 \mathrm{cc}$ compound, constituted by $0.25 \mathrm{cc}$ xylazine, $[25 \mathrm{cc}, 20 \mathrm{mg} / \mathrm{cc}$ ] and $0.25 \mathrm{cc}$ ketamine hydrochloride [1000, $100 \mathrm{mg} / \mathrm{cc}, 10 \mathrm{cc}] .0 .03 \mathrm{cc}$ butorphanol $[10 \mathrm{mg} / \mathrm{cc}, 10 \mathrm{cc}]$ anaesthesia was followed S.C. before laparotomy. Rats were 1618 weeks old. They were randomly assigned to four (4) groups consisted in $\mathrm{N}=10$. The common stage of $45 \mathrm{~min}$ ischemia was preceded in all 4 groups. Afterwards, 60 min reperfusion was followed in group A; 120 min in group B; immediate Epo 
intravenous (IV) administration and 60 min reperfusion in group C; and immediate Epo IV administration $120 \mathrm{~min}$ in group $\mathrm{D}$. The dose height was assessed at pre-experimental phase as $10 \mathrm{mg} / \mathrm{Kg}$ body mass. Ischemia was induced by laparotomic clamping the inferior aorta upper the renal arteries level with forceps for $45 \mathrm{~min}$. The forceps removal was restoring the inferior aorta blood patency and reperfusion. Epo was administered at the time of reperfusion; through an inferior vena cava catheter. Finally, the sedated rats were administered by diazepam SQ injection with an insulin syringe in the flank area which was rarely felt. Once the rats were sedated, an intraperitoneal injection (IP; in the abdomen) of the correct dose of sodium pentobarbital was administered, also with insulin syringe in the lower right side of the abdomen. The EK and UC scores were determined at $60^{\text {th }}$ min of reperfusion (for $\mathrm{A}$ and $\mathrm{C}$ groups) and at $120^{\text {th }}$ min of reperfusion (for B and D groups). The pathologic score grading was maintained the same as in preliminary studies: (0-0.499) grade without lesions, (0.5$1.499)$ grade mild lesions, (1.5-2.499) grade moderate lesions and (2.5-3) grade serious lesions damage. Relation was raised between animals' mass with neither EK scores ( $p$-value $=0.0692$ ) nor with UC ones (p-values=0.5769).

\section{The ischemia-reperfusion injury model}

\section{Placebo groups}

The 20 placebo rats were the same for preliminaries and this study.

\section{Group A}

$60 \mathrm{~min}$ reperfusion concerned 10 placebo rats of combined EK and predicted UC (EK\&UC) score as the mean of EK score and UC one (Table 1).

\section{Group B}

120 min reperfusion concerned 10 placebo rats of combined EK\&UC (cEK\&UC) score as the mean of EK and predicted UC one (Table 1).

\section{Epo group}

The $20 \mathrm{~L}$ rats were the same for preliminaries and this study.

\section{Group C}

60 min reperfusion concerned 10 Epo rats of cEK\&UC score as the mean of EK score and predicted UC one (Table 1).

\section{Group D}

120 min reperfusion concerned 10 Epo rats of cEK\&UC score as the mean of EK score and predicted UC one (Table 1).

\section{Statistical Analysis}

Successive comparisons among the 4 cEK\&UC groups were performed applying Wilcoxon signed-rank test (Table 2). Then, the generalized linear models (glm) were applied with dependant variable the cEE\&UI scores Independent variables were used the Epo administration or no, the reperfusion time and their interaction.

\section{Results}

Epo administration non-significantly recessed the cEK\&UC scores by without lesions 0.275 [-0.6702756- 0.01202756] ( $\mathrm{p}=0.1595$ and 0.1671 ) by Wilcoxon signed-rank test and glm methods respectively. Reperfusion time also non-significantly recessed the cEK\&UC scores by between without lesions 0.125 [-0.3168828 - 0.5668828] $(\mathrm{p}=0.4046)$ and without lesions 0.025 [-0.430378 - 0.380378] $(\mathrm{p}=0.9013)$ by Wilcoxon signed-rank test and glm methods respectively. However, erythropoietin administration and reperfusion time together also nonsignificantly recessed the cEE\&UI scores by without lesions 0.1409091 [-0.3809924-0.0991742] $(\mathrm{p}=0.2421)$. A concise form of the above findings is depicted at table 3 and 4 .

Table 1: Endometrial karyorrhexis (EK), Uterus congestion (UC) and their mean and SD scores.

\begin{tabular}{|c|c|c|c|}
\hline & $\begin{array}{c}\text { Mean EK score } \\
\text { +SD }\end{array}$ & $\begin{array}{c}\text { Mean UC score } \\
\text { +SD }\end{array}$ & $\begin{array}{c}\text { Mean EK\&UC score } \\
\text { +SD }\end{array}$ \\
\hline $\begin{array}{c}\text { Group } \\
\text { A }\end{array}$ & $\begin{array}{c}\text { mild lesions } 1 \pm \\
0.942809\end{array}$ & $\begin{array}{c}\text { mild lesions 1.4 } \pm \\
0.5163978\end{array}$ & $\begin{array}{c}\text { mild lesions } 1.2 \pm \\
0.4830459\end{array}$ \\
\hline Group & mild lesions 1.1 & mild lesions 1.1 \pm & mild lesions $1.1 \pm$ \\
B & \pm 0.875595 & 0.3162278 & 0.4594683 \\
\hline Group & mild lesions 0.8 & mild lesions 0.9 \pm & mild lesions $0.85 \pm$ \\
C & \pm 0.7888106 & 0.5676462 & 0.6258328 \\
\hline Group & mild lesions 0.5 & mild lesions 1.3 \pm & mild lesions $0.9 \pm$ \\
D & \pm 0.9718253 & 0.9486833 & 0.875595 \\
\hline
\end{tabular}

Table 2: The values difference for groups (DG) after Wilcoxon signedrank test for mean EK \& UC scores.

\begin{tabular}{|c|c|c|}
\hline DG & Difference & p-value \\
\hline A-B & -0.1 & 0.5632 \\
\hline A-C & -0.35 & 0.3004 \\
\hline A-D & -0.3 & 0.3213 \\
\hline B-C & -0.25 & 0.3941 \\
\hline B-D & -0.2 & 0.3458 \\
\hline C-D & +0.05 & 0.9180 \\
\hline
\end{tabular}

Table 3: The alteration influence of erythropoietin in connection with reperfusion time-p-values.

\begin{tabular}{|c|c|c|c|c|}
\hline Alteration & $95 \%$ c. in. & $\begin{array}{c}\text { Reperfusion } \\
\text { time }\end{array}$ & wilkoxon & glm \\
\hline $\begin{array}{l}\text { without lesions } \\
-0.35\end{array}$ & $\begin{array}{c}-1.004116- \\
0.304116\end{array}$ & $1 \mathrm{~h}$ & 0.3004 & \\
\hline $\begin{array}{l}\text { without lesions } \\
0.1\end{array}$ & $\begin{array}{c}-0.3429133- \\
0.5429133\end{array}$ & $1 \mathrm{~h}$ & & 0.6410 \\
\hline $\begin{array}{l}\text { without lesions } \\
-0.275\end{array}$ & $\begin{array}{c}-0.6702756- \\
.01202756\end{array}$ & $1.5 \mathrm{~h}$ & 0.1595 & 0.1671 \\
\hline $\begin{array}{l}\text { without lesions } \\
-0.2\end{array}$ & $\begin{array}{c}-0.6828291- \\
0.2828291\end{array}$ & $2 \mathrm{~h}$ & 0.3458 & \\
\hline $\begin{array}{l}\text { without lesions } \\
-0.05\end{array}$ & $\begin{array}{c}-0.765034- \\
0.665034\end{array}$ & $2 \mathrm{~h}$ & & 0.8848 \\
\hline $\begin{array}{l}\text { without lesions } \\
-0.025\end{array}$ & $\begin{array}{c}-0.430378- \\
0.380378\end{array}$ & reperfusion & & 0.9013 \\
\hline $\begin{array}{l}\text { without lesions } \\
-0.125\end{array}$ & $\begin{array}{c}-0.3168828- \\
0.5668828\end{array}$ & reperfusion & 0.4046 & \\
\hline $\begin{array}{l}\text { without lesions } \\
-0.1409091\end{array}$ & $\begin{array}{c}-0.3809924- \\
0.0991742\end{array}$ & interaction & & 0.2421 \\
\hline
\end{tabular}

Citation: Tsompos C, Panoulis C, Toutouzas K, Triantafyllou A, Zografos CG, et al. (2018) The Co-Evaluation of Endometrial Karyorrhexis and Uterus Congestion after Erythropoietin Effect on Uterine Ischemia Reperfusion Injury. J Network Med Target Ther 1(2): dx.doi. 
Table 4: Concise form of the table 3.

\begin{tabular}{|l|c|c|}
\hline \multicolumn{1}{|c|}{ Increase } & $95 \%$ c. in. & Reperfusion time \\
\hline without lesions -0.125 & $-.67351465-0.42351465$ & $1 \mathrm{~h}$ \\
\hline without lesions -0.275 & $-0.6702756-0.1202756$ & $1.5 \mathrm{~h}$ \\
\hline without lesions -0.125 & $-.72393155-.47393155$ & $2 \mathrm{~h}$ \\
\hline without lesions -0.075 & $-.3736304-0.4736304$ & 0.1633 \\
\hline without lesions -0.1409091 & $-0.3809924-0.0991742$ & reperfusion \\
\hline
\end{tabular}

Table 5: The erythropoietin (Epo) influence ( $( \pm S D)$ on the levels of 34 seric variables of complete blood count and blood chemistry tests versus reperfusion (rep) time.

\begin{tabular}{|l|c|c|c|c|c|c|c|c|}
\hline 34 Variables & 1h rep & p-value & $1.5 h$ rep & p-value & 2h rep & p-value interaction of Epo and rep & p-value \\
\hline Mean & $+3.52 \% \pm 12.31 \%$ & 0.5694 & $+4.60 \% \pm 14.69 \%$ & 0.3743 & $+5.69 \% \pm 18.79 \%$ & 0.3463 & $+2.93 \% \pm 7.21 \%$ & 0.4114 \\
\hline
\end{tabular}

\section{Discussion}

Thaete LG, et al. [3] used Pep-1 (inhibits low-molecularweight hyaluronan (LMW-HA) due to binding to toll-like receptor 4 [TLR4]). TLR4 has a regulatory role for two antiinflammatory cytokines: the interferon-B1 decreased in wildtype mice and the interleukin-10 increased in TLR4-deficient mice $(\mathrm{P}<0.001)$, in response to UIR. Pep-1 completely inhibited the UIR induced fetal growth restriction (FGR) $(\mathrm{P}<0.001)$, ascribing possible roles for the endogenous TLR4 ligand LMW-HA in UIR induced FGR. FGR is up to both TLR4 and endogenous ligand(s), including the breakdown products of HA. In addition, TLR4 plays a role in staving pregnancy loss after UIR. Reiter RJ, et al. [4] described placenta, in particular, often as a site of excessive free radical production due to suboptimal adhesion to the uterine wall, which leads to either persistent or intermittent hypoxia or re-oxygenation. Both of these processes cause massive free radical production and organ dysfunction. These may induce pre-eclampsia and other disorders associating the pregnancy. Melatonin has prevented the above in non-human mammals. The optimal maternal circadian rhythmicity via the melatonin rhythm, oscillates the developing one of the fetus. However, disturbed maternal circadian rhythms, known as chronodisruption, and disturbed melatonin cycles have ominous consequences for the maturing fetal oscillators, which may lead to neonatal psychological and behavioral problems. Melatonin, of any origin, promotes fetal maturation and placenta/uterine homeostasis. The peripheral reproductive organs circadian clock genes have important roles in reproductive and organismal (fetal and maternal) physiology. Indoleamine may be beneficial for the treatment of pre-eclampsia, intrauterine growth restriction (IUGR), placental and fetal IR. This benefit is due to the possible antioxidant actions of melatonin along with its virtual absence of toxicity. The nocturnal propensity for parturition may relate with the interaction of nocturnal increase in melatonin with oxytocin. Sahin S, et al. [5] indicated that immunosuppressant tacrolimus reduces oxidative damage in rat UIR Histologic evaluation revealed that tacrolimus attenuates the inflammatory response and protects the tissue damage induced by UIR in rats. Alawadhi F, et al. [6] improved fertility after bone marrow derived stem cells (BMDSC) transplant in Asherman's Syndrome mice, demonstrating a potential novel prevention and treatment for murine Asherman's Syndrome after uterine injury. Trifonova EA, et al. [7] studied a cluster of 63 differentially expressed genes (DEG) up-regulated in preeclampsia patients including not only the known candidate genes identified in many other genome-wide studies (e.g, BHLHB2, LEP, SIGLEC6, BCL6, RDH13), but also new ones (SYDE1, ANKRD37, ITGB2, CYBA, etc.), considered as new biological markers of preeclampsia with increasing interest. So, the development of preeclampsia may be related with immune processes, a stress response, the intracellular signaling cascades, the regulation of cell-cell interactions, etc. Iran-Nejad A, et al. [8] found the uterus weight augmented by estradiol $(\mathrm{P}<0.05)$ after renal IR injury in female rats. Drobyshevsky A, et al. [9] showed a significant 3.72-fold hypoperfusion of the maternal placenta in reperfusion phase in the saline than the antioxidant group dynamic contrast enhanced (DCE) MRI, relative to pre-occlusion values correspondingly. 31\% systematic hypo perfusion of placenta by steepest slope DCE MRI is significant on fetal antenatal ischemia in a rabbit model. Vafapour $\mathrm{M}$, et al. [10] found uterus weight decreased significantly in female rats treated with GABA. Atalay YO, et al. [11] found remifentanil to protect the UIR and thus safe in uterus transplantation in exposed rats. Talebi N, et al. [12] found the uterus weight increased significantly after estradiol administration $(\mathrm{P}<0.05)$ in ovariectomized rats. Tang Y, et al. [13] indicated that the soy isoflavone (SI) phytoestrogen, similar chemically with endogenous estrogen-estradiol; protects myocardial IR injury in ovariectomized rats increasing PI3K/Akt/eNOS signal pathway and decreasing the oxidative stress. Ingles J, et al. [14] defined the preconditioning as "the preparation for a subsequent action." The unfolded protein response (UPR) is a cellular stress response controlled at the level of the endoplasmic reticulum. However, in the context of remote preconditioning, activation of these intracellular molecular pathways must result in the extracellular transmission of adaptive signals to remote targets. The activation of the UPR in the pregnant uterine myocyte may be associated with increased uterine myocyte quiescence and

Citation: Tsompos C, Panoulis C, Toutouzas K, Triantafyllou A, Zografos CG, et al. (2018) The Co-Evaluation of Endometrial Karyorrhexis and Uterus Congestion after Erythropoietin Effect on Uterine Ischemia Reperfusion Injury. J Network Med Target Ther 1(2): dx.doi. 
normal gestational length. A gestational stress-induced uterine paracrine secretome-for example, glucose-regulated protein 78 , with preconditioning-like properties - acts to promote both local and systemic tolerance to the ensuing gestational insults, allowing for the maintenance of uterine quiescence. In this context, preterm labor may be the result of a pregnant uterus experiencing a stress it cannot accommodate or when it is unable to host an appropriate UPR resulting in insufficient preconditioning and a diminished local and systemic capacity to tolerate pregnancy-dependent increases in normal gestational stress; in order to prolong uterine quiescence in pregnancy. Tricard J, et al. [15] revealed a moderate inflammation of the endometrium and serosa at $90 \mathrm{~min}$ following reperfusion in the 3-h group and severe inflammation in the 24 -h group. These first macroscopic and histological results suggest that the uterus is an organ with a good tolerance to extended cold ischemic storage before transplantation in ewes. Aslan $M$, et al. [16] found antioxidant effects on the uterus and specially a cellular damage of uterus reduce in oxytocin and kisspeptin administered IR group than only kisspeptin one. A numeric evaluation [17] of the Epo efficacies was provided by a metaanalysis of 34 seric variables of complete blood count and blood chemistry tests versus reperfusion time coming from the same experimental setting (Table 5).

\section{Conclusion}

Epo has a non significant recessing potency for endometrial karyorrhexis and uterus congestion together ( $\mathrm{p}$-values $=0.2421$ ) creating a suspicion for beneficial usage in situations such as fetal growth restriction, pregnancy loss, pre-eclampsia, IUGR, placental and fetal IR, fertility, Asherman's syndrome, uterus transplantation, preterm labor, endometritis.

\section{Conflict of Interest}

The authors declare that there is no conflict of interest regarding the publication of this paper.

\section{Acknowledgement}

Acknowledged in preliminary studies

\section{References}

1. Tsompos C, Panoulis C, Toutouzas K, Triantafyllou A, Zografos G, et al. (2016) The Effect of Erythropoietin on Endometrial Karyorrhexis during Ischemia Reperfusion Injury in Rats. J Contracept Stud 1: 1-5.

2. Tsompos C, Panoulis C, Toutouzas K, Triantafyllou A, Zografos G, et al. (2017) The Erythropoietin Effect on Uterus Congestion after Uterine Ischemia Reperfusion. Transl Biomed.

3. Thaete LG, Qu XW, Jilling T, Crawford SE, Fitchev P, et al. (2013) Impact of toll-like receptor 4 deficiency on the response to uterine ischemia/reperfusion in mice. Reproduction 145: 517526.

4. Reiter RJ, Tan DX, Korkmaz A, Rosales-Corral SA (2014) Melatonin and stable circadian rhythms optimize maternal, placental and fetal physiology. Hum Reprod Update 20: 293-307.
5. Sahin S, Ozakpinar OB, Ak K, Eroglu M, Acikel M, et al. (2014) The protective effects of tacrolimus on rat uteri exposed to ischemia-reperfusion injury: a biochemical and histopathologic evaluation. Fertil Steril 101: 1176-1182.

6. Alawadhi F, Du H, Cakmak H, Taylor HS (2014) Bone MarrowDerived Stem Cell (BMDSC) transplantation improves fertility in a murine model of Asherman's syndrome. PLoS One 9: e96662.

7. Trifonova EA, Gabidulina TV, Ershov NI, Serebrova VN, Vorozhishcheva AY, et al. (2014) Analysis of the placental tissue transcriptome of normal and preeclampsia complicated pregnancies. Acta Naturae 6: 71-683.

8. Iran Nejad A, Nematbakhsh M, Eshraghi-Jazi F, Talebi A (2015) Preventive role of estradiol on kidney injury induced by renal ischemia-reperfusion in male and female rats. Int J Prev Med.

9. Drobyshevsky A, Prasad PV (2015) Placental perfusion in uterine ischemia model as evaluated by dynamic contrast enhanced MRI. J Magn Reson Imaging 42: 666-672.

10. Vafapour M, Nematbakhsh M, Monajemi R, Mazaheri S, Talebi A, et al. (2015) Effect of $\Gamma$-aminobutyric acid on kidney injury induced by renal ischemia-reperfusion in male and female rats: Gender-related difference. Adv Biomed Res.

11. Atalay YO, Aktas S, Sahin S, Kucukodaci Z, Ozakpinar OB (2015) Remifentanil protects uterus against ischemia-reperfusion injury in rats. Acta Cir Bras 30: 756-761.

12. Talebi N, Nematbakhsh M, Monajemi R, Mazaheri S, Talebi A, et al. (2016) The Protective Effect of $\gamma$-aminobutyric Acid on Kidney Injury Induced by Renal Ischemia-reperfusion in Ovariectomized Estradiol-treated Rats. Int J Prev Med.

13. Tang Y, Li S, Zhang P, Zhu J, Meng G, Xie L, et al. (2016) Soy Isoflavone Protects Myocardial Ischemia/Reperfusion Injury through Increasing Endothelial Nitric Oxide Synthase and Decreasing Oxidative Stress in Ovariectomized Rats. Oxid Med Cell Longev.

14. Ingles J, Kyathanahalli CN, Jeyasuria P, Condon JC (2017) Thinking Outside the Box-Application of Uterine Preconditioning in Pregnancy as a Novel Strategy to Mitigate Preterm Birth?. J Cardiovasc Pharmacol Ther 22: 337-346.

15. Tricard J, Ponsonnard S, Tholance $Y$, Mesturoux L, Lachatre $D$, et al. (2017) Uterus tolerance to extended cold ischemic storage after auto-transplantation in ewes. Eur J Obstet Gynecol Reprod Biol 214: 162-167.

16. Aslan M, Erkanli Senturk G, Akkaya H, Sahin S, Yılmaz B (2017) The effect of oxytocin and Kisspeptin-10 in ovary and uterus of ischemia-reperfusion injured rats. Taiwan J Obstet Gynecol 56: 456-462.

17. Tsompos C, Panoulis C, Toutouzas K, Triantafyllou A, Zografos G, et al. (2016) The Acute Effect of Erythropoietin on Mean Platelet Volume Levels during Hypoxia Reoxygenation Injury in Rats. Med Bull Haseki 54: 199-206.

Citation: Tsompos C, Panoulis C, Toutouzas K, Triantafyllou A, Zografos CG, et al. (2018) The Co-Evaluation of Endometrial Karyorrhexis and Uterus Congestion after Erythropoietin Effect on Uterine Ischemia Reperfusion Injury. J Network Med Target Ther 1(2): dx.doi. 